\title{
A Series Dynamic Resistor Based Converter Protection Scheme for Doubly-Fed Induction Generator during Various Fault Conditions
}

\author{
Jin Yang, Student Member, IEEE, John E. Fletcher, and John O'Reilly, Senior Member, IEEE
}

\begin{abstract}
This paper proposes a new converter protection method, primarily based on a series dynamic resistor (SDR), that avoids the doubly-fed induction generator (DFIG) control being disabled by crowbar protection during fault conditions. A combined converter protection scheme based on the proposed series dynamic resistor and conventional crowbar is analysed and discussed. The main protection advantages are due to the series topology when compared with crowbar and DC-chopper protection. Various fault over-current conditions (both symmetrical and asymmetrical) are analysed and used to design the protection in detail, including the switching strategy and coordination with crowbar, and resistance value calculations. PSCAD/EMTDC simulation results show that the proposed method is advantageous for fault over-current protection, especially for asymmetrical faults, in which the traditional crowbar protection may malfunction.
\end{abstract}

Index Terms-Series dynamic resistor (SDR), converter protection scheme, doubly-fed induction generator (DFIG), fault ride-through (FRT), wind power generation.

\section{NOMENCLATURE}

$\begin{array}{ll}\vec{v}, \vec{i}, \vec{\psi} & \text { Voltage, current and flux vectors. } \\ V_{s}, V_{r} & \text { Stator, rotor voltage amplitudes. } \\ R_{s}, R_{r} & \text { Stator, rotor resistances. } \\ L_{s}, L_{r}, L_{l s}, L_{l r} & \text { Stator, rotor self- and leakage inductances. } \\ L_{m} & \text { Magnetizing inductance. } \\ \omega_{s}, \omega_{r}, s \omega_{s} & \text { Synchronous, rotor and slip angular frequencies. } \\ \tau_{s}, \tau_{r}, \tau & \text { Stator, rotor and combined time constants. } \\ P_{s}, Q_{s} & \text { Stator side active and reactive power. } \\ s, r & \text { Stator and rotor subscripts. } \\ n & \text { Nominal value subscript. }\end{array}$

\section{INTRODUCTION}

L ARGE-SCALE offshore wind farms are gradually growing all around the world, especially in Europe where offshore wind resources are rich and located in shallow water. By 2020, $20 \%$ of power consumption in Europe will be supplied from renewable resources. The realization of this ambitious plan relies heavily on the large-scale offshore wind farms. For the UK's 2020 target, offshore wind farms will contribute as much as

J. Yang and J. O'Reilly are with the Department of Electronics and Electrical Engineering, University of Glasgow, G12 8LT, UK (e-mail: j.yang@elec.gla.ac.uk, j.oreilly@elec.gla.ac.uk).

J. E. Fletcher is with the Department of Electronic and Electrical Engineering, University of Strathclyde, G1 1XW, UK (e-mail: john.fletcher@eee.strath.ac.uk).
9.4\% [1]. There is now planning for more than $30 \mathrm{GW}$ of offshore wind farm capacity in the European seas by 2015 almost 30 times more than the current installation [2]. Therefore, the reliability of offshore wind farms needs to be assessed in detail because of the costly maintenance and repair in the offshore environment. The reliability is distributed between the wind turbines, the wind power generation systems, the collection grid and the transmission system [3].

For wind power generation systems, the doubly-fed induction generator (DFIG), with its variable wind speed tracking performance, and relatively low cost compared to fully-rated converter wind power generation system, e.g. permanent magnet synchronous generator (PMSG), is a popular wind generation concept. However, a significant disadvantage of the DFIG is its vulnerability to grid disturbances because the stator windings are connected directly to the grid through a transformer and switchgear with only the rotor-side buffered from the grid via a partially-rated converter. So as to protect the wind farm from interruptions due to onshore grid faults and wind farm faults, crowbar protects the induction generator and associated power electronics. This is widely-used in industrial applications.

A major disadvantage of crowbar protection is that the rotorside converter (RSC) has to be disabled when using the crowbar and the generator consumes reactive power leading to deterioration of grid voltage. In line with developing fault ridethrough (FRT) requirements, an active crowbar control scheme is proposed [4], [5] to shorten the time the crowbar is in operation but this does not avoid the reactive power consumption. Some researchers developed a new fault control strategy [6] or a faulttolerant series grid-side converter topology [7]. However, these make the control systems complex or increase the issues with control coordination between normal and fault operation.

A series topology can drop rotor circuit voltage hence limiting the current, and is an alternative to crowbar protection. However, to the authors' knowledge, there has been no published literature on a series topology protection schemes. Therefore this research assesses series protection for effective turbine and converter protection during various fault conditions.

The paper is organised as follows. In Section II, the existing protection schemes for variable-speed wind turbine generation systems, including DFIGs and permanent magnet synchronous generators, are summarised. Then a protection scheme with series dynamic resistor connected to the rotor winding is proposed. The faults that can occur in wind farms and the currents in the rotor windings of DFIGs are discussed in detail 
as the basis of the converter protection scheme design: fault rotor current expressions are given theoretically and with simulation results; and the difference between rotor current characteristics for symmetrical and asymmetrical faults is discussed which highlights the advantage series dynamic resistors as the primary protection of the converter. In Section IV, a new converter protection scheme combining the series dynamic resistor and the crowbar is introduced. Analysis and discussion of PSCAD/EMTDC simulations are provided in Section III and V.

\section{CONVERTER PROTECTION SCHEMES FOR DFIG}

\section{A. Crowbar Protection}

The prevalent DFIG protection scheme is crowbar protection. A crowbar is a set of resistors that are connected in parallel with the rotor winding on occurrence of an interruption, bypassing the rotor-side converter. The active crowbar control scheme connects the crowbar resistance when necessary and disables it to resume DFIG control.

For active crowbar control schemes, the control signals are activated by the rotor-side converter devices (which are usually IGBTs). These have voltage and current limits that must not be exceeded. Therefore the rotor-side converter voltages and currents are the critical regulation reference. The DC-link bus voltage can increase rapidly under these conditions, so it is also used as a monitored variable for crowbar triggering. $\mathrm{Bi}$ directional thyristors [8], GTOs [5], [9] or IGBTs [10] are typically used for crowbar switching.

\section{B. DC-Chopper}

In [5], [11] a braking resistor (DC-chopper) is connected in parallel with the DC-link capacitor to limit the overcharge during low grid voltage. This protects the IGBTs from overvoltage and can dissipate energy, but this has no effect on the rotor current. It is also used as protection for the DC-link capacitor in full rated converter topologies, for example, permanent magnet synchronous generators [12].

\section{Series Dynamic Resistor (SDR)}

In a similar way to the series dynamic braking resistor [13], which has been used in the stator side of generators, a dynamic resistor is proposed to be put in series with the rotor (series dynamic resistor) and this limits the rotor over-current. Being controlled by a power-electronic switch, in normal operation, the switch is on and the resistor is bypassed; during fault conditions, the switch is off and the resistor is connected in series to the rotor winding.

The difference between the series dynamic resistor and the crowbar or DC-link braking resistor is its topology. The latter are shunt-connected and control the voltage while the series dynamic resistor has the distinct advantage of controlling the current magnitude directly. Moreover, with the series dynamic resistor, the high voltage will be shared by the resistance because of the series topology, so the induced overvoltage may not lead to the loss of converter control. Therefore it not only controls the rotor overvoltage which could cause the rotor-side converter to lose

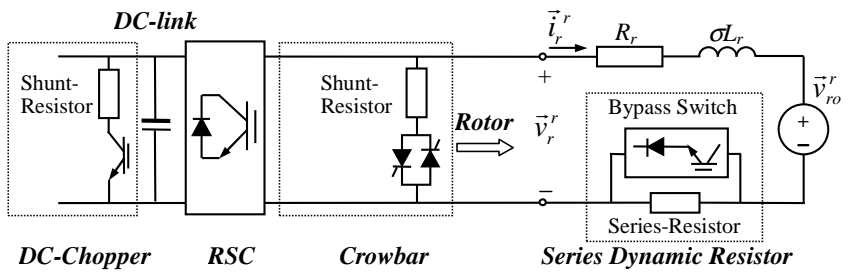

Fig. 1. DFIG rotor equivalent circuit with all protection schemes shown.

control, but, more significantly, limits high rotor current. In addition, the limited current can reduce the charging current to the DC-link capacitor, hence avoiding DC-link overvoltage. So with the series dynamic resistor, the rotor-side converter does not need to be inhibited during the fault.

The crowbar is adequate for protection of the wind turbine system during grid faults in on-shore developments. The influence of temporarily losing rotor-side control of DFIGs can be neglected - which is not presently the case for large-scale offshore wind farms. The series topology is straightforward enough to limit the over-current and share overvoltage but there appears to be no literature investigating their use.

To show the protection schemes and their interaction with the rotor circuit, the rotor equivalent circuit is described first with the general Park's model of induction generators. From the voltage and flux equations of induction generators in a static statororiented reference frame [14]:

$$
\begin{gathered}
\vec{v}_{s}=R_{s} \vec{i}_{s}+\frac{d \vec{\psi}_{s}}{d t} \\
\vec{v}_{r}=R_{r} \vec{i}_{r}+\frac{d \vec{\psi}_{r}}{d t}-j \omega_{r} \vec{\psi}_{r} \\
\vec{\psi}_{s}=L_{s} \vec{i}_{s}+L_{m} \vec{i}_{r} \\
\vec{\psi}_{r}=L_{m} \vec{i}_{s}+L_{r} \vec{i}_{r}
\end{gathered}
$$

where $\vec{v}_{s}$ is imposed by the grid. The rotor voltage $\vec{v}_{r}$ is controlled by the rotor-side converter and used to perform generator control.

From (3) and (4) we can eliminate $\vec{i}_{s}$ and obtain an expression which is substituted into (2); eliminating $\vec{\psi}_{r}$ gives

$$
\vec{v}_{r}=\frac{L_{m}}{L_{s}}\left(\frac{d}{d t}-j \omega_{r}\right) \vec{\psi}_{s}+\left[R_{r}+L_{r}\left(1-\frac{L_{m}^{2}}{L_{s} L_{r}}\right)\left(\frac{d}{d t}-j \omega_{r}\right)\right] \cdot \vec{i}_{r} \cdot(5)
$$

Defining the leakage factor as $\sigma=1-\frac{L_{m}^{2}}{L_{s} L_{r}}$.

Then use a voltage source $\vec{v}_{r o}$ to represent the voltage due to the

stator flux produces $\vec{v}_{r o}=\frac{L_{m}}{L_{s}}\left(\frac{d}{d t}-j \omega_{r}\right) \vec{\psi}_{s}$.

So (5) becomes

$$
\vec{v}_{r}=\vec{v}_{r o}+\left[R_{r}+\sigma L_{r}\left(\frac{d}{d t}-j \omega_{r}\right)\right] \cdot \vec{i}_{r} .
$$

The rotor voltage in (8) can be expressed in a rotor reference frame (i.e. multiply both sides by $e^{-j \omega_{r} t}$ )

$$
\vec{v}_{r}^{r}=\vec{v}_{r o}^{r}+R_{r} \cdot \vec{i}_{r}^{r}+\sigma L_{r} \frac{d \vec{i}_{r}^{r}}{d t} .
$$

This is the relationship between rotor voltage and current. So the rotor equivalent circuit is obtained and shown with all the above protection schemes in Fig. 1. 


\section{DFIG ROTOR CURRENTS DURING FAULT CONDITIONS}

DFIG rotor currents under three-phase short-circuit fault have been thoroughly analysed. In [15], exact expressions of stator and rotor currents during the short-circuit are derived mathematically. The approximate maximum stator fault current expression was also discussed from the analysis of DFIG physical response with crowbar protection [8]. However, there has been no analysis of fault currents during less serious voltage dips or asymmetrical disturbances. Nonetheless, this is important for the design of DFIG protection systems. In this paper, the rotor current expressions during various fault conditions will be deduced on the basis of the analysis of [14], [16].

The phase $a$ voltage expression is

$$
v_{r a}(t)=\operatorname{Re}\left\{\vec{v}_{r o}^{r}\right\}+R_{r} \cdot i_{r a}(t)+\sigma L_{r} \frac{d i_{r a}(t)}{d t} .
$$

This can be written as a linear differential equation for $i_{r a}(t)$

$$
i_{r a}^{\prime}(t)+\frac{R_{r}}{\sigma L_{r}} i_{r a}(t)=\frac{1}{\sigma L_{r}}\left[v_{r a}(t)-\operatorname{Re}\left\{\vec{v}_{r o}^{r}\right\}\right]
$$

where with converter in operation, let $v_{r a}(t)=V_{r} \cos \left(s \omega_{s} t+\beta\right), \beta$ is the phase $a$ rotor voltage angle at the instant the fault occurs.

\section{A. Symmetrical fault conditions}

For a symmetrical voltage disturbance on the stator side, if there is a three-phase step amplitude change from $V_{s}$ to $(1-p) V_{s}(p$ is the voltage dip ratio), $\vec{v}_{r o}^{r}$ in (9) can exceed the maximum voltage that the rotor converter can generate, which causes the failure of current control. The voltage is [16]

$$
\vec{v}_{r o}^{r}=(1-p) V_{s} \frac{L_{m}}{L_{s}} s e^{j s \omega_{s} t}-\frac{L_{m}}{L_{s}}\left(\frac{1}{\tau_{s}}+j \omega_{r}\right) \frac{p V_{s}}{j \omega_{s}} e^{-\frac{t}{\tau_{s}}} .
$$

With time constants defined as

$$
\tau_{r}=\sigma L_{r} / R_{r} ; \tau_{s}=L_{s} / R_{s} ; \tau=\left(\tau_{r} \tau_{s}\right) /\left(\tau_{s}-\tau_{r}\right)
$$

(12) can be simplified by omitting $1 / \tau_{s}$, which is very small because of the small stator resistance of the generator, so

$$
\vec{v}_{r o}^{r} \approx V_{s} \frac{L_{m}}{L_{s}}\left[s(1-p) e^{j s \omega_{s} t}-(1-s) p e^{-j \omega_{r} t} e^{-\frac{t}{\tau_{s}}}\right] .
$$

From (11) and (14), the final expression of $i_{r a}(t)$ can be solved and divided into four components

$$
i_{r a}(t)=i_{D C}+i_{v r}+i_{v r f}+i_{v r n}
$$

where the components are

$$
\begin{aligned}
i_{D C}= & \left\{i_{r a}\left(t_{0}^{-}\right)-\frac{1}{\sigma L_{r}} \frac{\tau_{r}}{1+\tau_{r}^{2}\left(s \omega_{s}\right)^{2}}\left[V_{r} \cos \beta-V_{s} \frac{L_{m}}{L_{s}} s(1-p)\right]\right. \\
i_{v r}= & \frac{V_{r}}{\sigma L_{r}}\left[\frac{1}{\sigma L_{r}} V_{s} \frac{\tau_{r}}{L_{s}}(1-s) p \frac{\tau}{1+\tau_{r}^{2} \omega_{r}^{2}} \cos \left(s \omega_{s} t+\beta\right)+\frac{\tau_{r}^{2} \omega_{r}}{1+\tau_{r}^{2} \omega_{r}^{2}} \sin \left(s \omega_{s} t+\beta\right)\right] \\
i_{v r f}= & -\frac{1}{\sigma L_{r}} V_{s} \frac{L_{m}}{L_{s}} s(1-p) \times \\
& {\left[\frac{\tau_{r}}{1+\tau_{r}^{2}\left(s \omega_{s}\right)^{2}} \cos \left(s \omega_{s} t\right)+\frac{\tau_{r}^{2} s \omega_{s}}{1+\tau_{r}^{2}\left(s \omega_{s}\right)^{2}} \sin \left(s \omega_{s} t\right)\right] } \\
i_{v r n}= & \frac{V_{s}}{\sigma L_{r}} \frac{L_{m}}{L_{s}}(1-s) p \times\left[\frac{\tau}{1+\tau^{2} \omega_{r}^{2}} \cos \left(\omega_{r} t\right)+\frac{\tau^{2} \omega_{r}}{1+\tau^{2} \omega_{r}^{2}} \sin \left(\omega_{r} t\right)\right] e^{-\frac{t}{\tau_{s}}} .
\end{aligned}
$$

The components are listed in TABLE I with frequency and decaying-time constant characteristics.
TABLE I SYMMETRICAL FAULT ROTOR CURRENT COMPONENTS

\begin{tabular}{c|c|c}
\hline Component & Frequency & Decaying-time constant \\
\hline$i_{D C}$ & $\mathrm{DC}$ & $\tau_{r}$ \\
\hline$i_{v r}$ & $s \omega_{s}$ & - \\
\hline$i_{v r f}$ & $s \omega_{s}$ & - \\
\hline$i_{v r n}$ & $\omega_{r}$ & $\tau_{s}$ \\
\hline
\end{tabular}

\section{B. Asymmetrical fault conditions}

For asymmetrical faults, the stator voltage is divided into three parts: positive, negative and zero sequence components, in the use of symmetrical components theory [16]:

$$
\vec{v}_{s}=\vec{V}_{s 1} e^{j \omega_{s} t}+\vec{V}_{s 2} e^{-j \omega_{s} t}+\vec{V}_{s 0}
$$

Then $\vec{v}_{r o}^{r}$ in (9) can also be expressed as

$$
\vec{v}_{r o}^{r}=\vec{v}_{r 1}^{r}+\vec{v}_{r 2}^{r}+\vec{v}_{r n}^{r}
$$

where

$$
\vec{v}_{r 1}^{r}=V_{s 1} \frac{L_{m}}{L_{s}} s e^{j s \omega_{s} t}
$$

$$
\begin{aligned}
& \vec{v}_{r 2}^{r}=V_{s 2} \frac{L_{m}}{L_{s}}(s-2) e^{-j(2-s) \omega_{s} t} \\
& \vec{v}_{r n}^{r} \approx-j \omega_{r} \frac{L_{m}}{L_{s}} \vec{\psi}_{n 0} e^{-\frac{t}{\tau_{s}}} e^{-j \omega_{r} t}
\end{aligned}
$$

The components $\vec{V}_{s 1}, \vec{V}_{s 2}, \vec{V}_{s 0}$, and $\vec{\psi}_{n 0}$ depend on the type of fault.

\section{1) Single-Phase Voltage Dip:}

Phase $a$ suffers a voltage dip. The positive, negative and zero sequence components of the stator voltage are

$$
\left\{\begin{array}{l}
\vec{V}_{s 1}=V_{s}(1-p / 3) \\
\vec{V}_{s 2}=V_{s}(-p / 3) \\
\vec{V}_{s 0}=V_{s}(-p / 3)
\end{array}\right.
$$

where $p$ is the phase $a$ voltage dip ratio due to the fault. So the above $\vec{v}_{r 0}^{r}$ components are

$$
\begin{gathered}
\vec{v}_{r 1}^{r}=V_{s}(1-p / 3) \frac{L_{m}}{L_{s}} s e^{j s \omega_{s} t} \\
\vec{v}_{r 2}^{r}=V_{s}(-p / 3) \frac{L_{m}}{L_{s}}(s-2) e^{-j(2-s) \omega_{s} t}
\end{gathered}
$$

From the natural flux initial value analysis in [16]

$$
\begin{gathered}
\vec{\psi}_{n 0}=\frac{V_{s}(2 / 3) p}{\omega_{s}} \\
\vec{v}_{r n}^{r} \approx-j \frac{2}{3} V_{s} \frac{L_{m}}{L_{s}}(1-s) p e^{-\frac{t}{\tau_{s}}} e^{-j \omega_{r} t} . \\
\vec{v}_{r o} \approx V_{s} \frac{L_{m}}{L_{s}} s\left(1-\frac{p}{3}\right) e^{j s \omega_{s} t}-V_{s} \frac{L_{m}}{L_{s}}(s-2) \frac{p}{3} e^{-j(2-s) \omega_{s} t} \\
-j \frac{2}{3} V_{s} \frac{L_{m}}{L_{s}}(1-s) p e^{-\frac{t}{\tau_{s}}} e^{-j \omega_{r} t}
\end{gathered}
$$

From (11) and (30) the final expression of $i_{r a}(t)$ can be solved and divided into five components

$$
i_{r a}(t)=i_{D C}+i_{v r}+i_{v r 1}+i_{v r 2}+i_{v r n}
$$

where the components are solved as:

$$
\begin{aligned}
& i_{D C}=\left\{i_{r a}\left(t_{0}^{-}\right)-\frac{1}{\sigma L_{r}} \frac{\tau_{r}}{1+\tau_{r}^{2}\left(s \omega_{s}\right)^{2}}\left[V_{r} \cos \beta-V_{s} \frac{L_{m}}{L_{s}} s\left(1-\frac{p}{3}\right)\right]\right. \\
& \left.-\frac{1}{\sigma L_{r}} V_{s} \frac{L_{m}}{L_{s}}\left[(s-2) \frac{p}{3} \frac{\tau_{r}}{1+\tau_{r}^{2}(2-s)^{2} \omega_{s}^{2}}+\frac{2}{3}(1-s) p \frac{-\tau^{2} \omega_{r}}{1+\tau^{2} \omega_{r}^{2}}\right]\right\} e^{-\frac{t}{\tau_{r}}}
\end{aligned}
$$




$$
\begin{aligned}
i_{v r}= & \frac{V_{r}}{\sigma L_{r}}\left[\frac{\tau_{r}}{1+\tau_{r}^{2} \omega_{r}^{2}} \cos \left(s \omega_{s} t+\beta\right)+\frac{\tau_{r}^{2} \omega_{r}}{1+\tau_{r}^{2} \omega_{r}^{2}} \sin \left(s \omega_{s} t+\beta\right)\right] \\
i_{v r 1}= & -\frac{V_{s}}{\sigma L_{r}} \frac{L_{m}}{L_{s}} s\left(1-\frac{p}{3}\right) \times\left[\frac{\tau_{r}}{1+\tau_{r}^{2}\left(s \omega_{s}\right)^{2}} \cos \left(s \omega_{s} t\right)+\frac{\tau_{r}^{2} s \omega_{s}}{1+\tau_{r}^{2}\left(s \omega_{s}\right)^{2}} \sin \left(s \omega_{s} t\right)\right] \\
i_{v r 2}= & \frac{1}{\sigma L_{r}} V_{s} \frac{L_{m}}{L_{s}}(s-2) \frac{p}{3} \times\left[\frac{\tau_{r}}{1+\tau_{r}^{2}(2-s)^{2} \omega_{s}^{2}} \cos \left((2-s) \omega_{s} t\right)\right. \\
& \left.+\frac{\tau_{r}^{2}(2-s) \omega_{s}}{1+\tau_{r}^{2}(2-s)^{2} \omega_{s}^{2}} \sin \left((2-s) \omega_{s} t\right)\right] \\
i_{v r n}= & \frac{2}{3} \frac{V_{s}}{\sigma L_{r}} \frac{L_{m}}{L_{s}}(1-s) p \times\left[\frac{-\tau^{2} \omega_{r}}{1+\tau^{2} \omega_{r}^{2}} \cos \left(\omega_{r} t\right)+\frac{\tau}{1+\tau^{2} \omega_{r}^{2}} \sin \left(\omega_{r} t\right)\right] e^{-\frac{t}{\tau_{s}}}
\end{aligned}
$$

\section{2) Phase-to-Phase Fault:}

Here phase $b$ and $c$ are short circuited leading to a voltage dip at the terminals. Then the positive, negative and zero sequence components of the stator voltage are

$$
\left\{\begin{array}{l}
\vec{V}_{s 1}=V_{s}(1-p / 2) \\
\vec{V}_{s 2}=V_{s}(p / 2) \\
\vec{V}_{s 0}=V_{s}(p / 2)
\end{array}\right.
$$

where $p$ is the phase $b$ and $c$ voltage dip ratio due to the fault. Also, the initial value of natural flux is [16]:

$$
\vec{\psi}_{n 0}=\frac{V_{s} p}{\omega_{s}}
$$

The current expression in this case is similar to the singlephase fault case, with the same five components, but different amplitudes. The components are solved as:

$$
\begin{aligned}
& i_{D C}=\left\{i_{r a}\left(t_{0}^{-}\right)-\frac{1}{\sigma L_{r}} \frac{\tau_{r}}{1+\tau_{r}^{2}\left(s \omega_{s}\right)^{2}}\left[V_{r} \cos \beta-V_{s} \frac{L_{m}}{L_{s}} s\left(1-\frac{p}{2}\right)\right]\right. \\
& \left.+\frac{1}{\sigma L_{r}} V_{s} \frac{L_{m}}{L_{s}}\left[(s-2) \frac{p}{2} \frac{\tau_{r}}{1+\tau_{r}^{2}(2-s)^{2} \omega_{s}^{2}}-(1-s) p \frac{-\tau^{2} \omega_{r}}{1+\tau^{2} \omega_{r}^{2}}\right]\right\} e^{-\frac{t}{\tau_{r}}} \\
& i_{v r}=\frac{V_{r}}{\sigma L_{r}}\left[\frac{\tau_{r}}{1+\tau_{r}^{2} \omega_{r}^{2}} \cos \left(s \omega_{s} t+\beta\right)+\frac{\tau_{r}^{2} \omega_{r}}{1+\tau_{r}^{2} \omega_{r}^{2}} \sin \left(s \omega_{s} t+\beta\right)\right] \\
& i_{v r 1}=-\frac{V_{s}}{\sigma L_{r}} \frac{L_{m}}{L_{s}} s\left(1-\frac{p}{2}\right) \times\left[\frac{\tau_{r}}{1+\tau_{r}^{2}\left(s \omega_{s}\right)^{2}} \cos \left(s \omega_{s} t\right)+\frac{\tau_{r}^{2} s \omega_{s}}{1+\tau_{r}^{2}\left(s \omega_{s}\right)^{2}} \sin \left(s \omega_{s} t\right)\right] \\
& i_{v r 2}=-\frac{1}{\sigma L_{r}} V_{s} \frac{L_{m}}{L_{s}}(s-2) \frac{p}{2} \times\left[\frac{\tau_{r}^{2}(2-s) \omega_{s}}{1+\tau_{r}^{2}(2-s)^{2} \omega_{s}^{2}} \cos \left((2-s) \omega_{s} t\right)\right. \\
& \left.\quad+\frac{\tau}{1+\tau_{r}^{2} \omega_{s}^{2}} \sin \left((2-s) \omega_{s} t\right)\right] \\
& i_{v r n}=\frac{1}{\sigma L_{r}} V_{s} \frac{L_{m}}{L_{s}}(1-s) p \times\left[\frac{-\tau^{2} \omega_{r}}{1+\tau^{2} \omega_{r}^{2}} \cos \left(\omega_{r} t\right)\right] e^{-\frac{t}{\tau_{s}}}
\end{aligned}
$$

The components are listed in TABLE II with frequency and decaying-time constant characteristics:

TABLE II ASYMMETRICAL FAULT ROTOR CURRENT COMPONENTS

\begin{tabular}{c|c|c}
\hline Component & Frequency & Decaying time constant \\
\hline$i_{D C}$ & DC & $\tau_{r}$ \\
\hline$i_{v r}$ & $s \omega_{s}$ & - \\
\hline$i_{v r 1}$ & $s \omega_{s}$ & - \\
\hline$i_{v r 2}$ & $(2-s) \omega_{s}$ & - \\
\hline$i_{v r n}$ & $\omega_{r}$ & $\tau_{s}$ \\
\hline
\end{tabular}

(a)

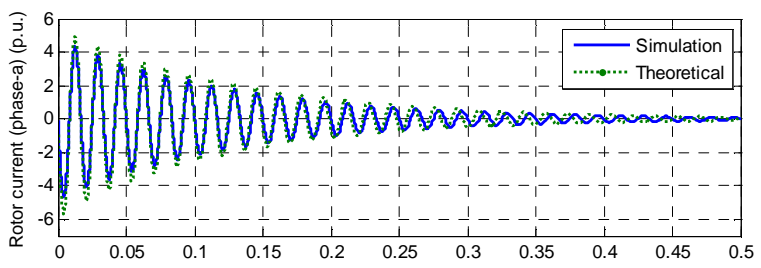

(b)

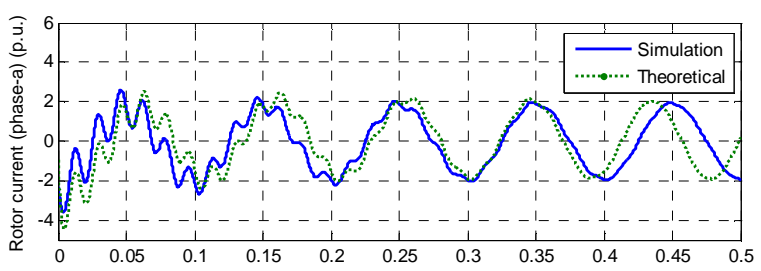

(c)

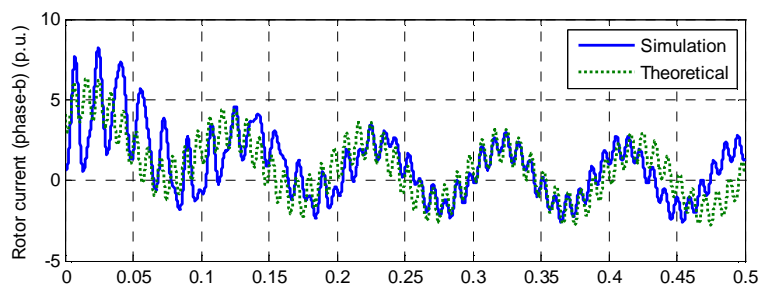

(d)

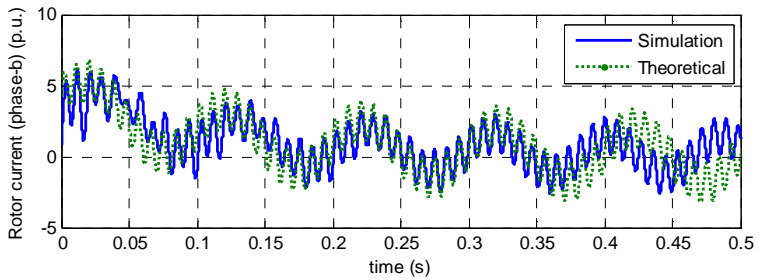

Fig. 2. The comparison of simulation and theoretical rotor currents during fault conditions (for 0.5s): (a) three-phase 1.0p.u. voltage dip; (b) three-phase 0.6p.u. voltage dip; (c) single-phase (phase $a$ ) voltage dip of 1.0p.u.; (d) phase-to-phase (phase $b$ to $c$ ) short circuit.

The fault rotor currents are simulated in PSCAD/EMTDC to compare with the analysis, as shown in Fig. 2. The generator parameters are shown in the Appendix, and the rotor side converter is controlled using a voltage regulating vectorcontroller. The simulations have the rotor-side converter connected when faults occur.

Each fault displays different frequency components and characteristics. The three-phase short-circuit fault causes an abrupt change at the moment the fault with highest peak values but with relatively short duration, Fig. 2(a) and Fig 3(a). However, for the less serious voltage dip and asymmetrical faults, Fig 2(bd), the high magnitude, high frequency oscillation makes it is impossible to switch off the crowbar protection. To protect the system, the converter has to be inhibited and then the DFIG absorbs reactive power from the grid, which is adversely affects grid recovery.

The comparisons show that the analysis is in accordance with theory and is valid for the study of the fault conditions. Therefore it will contribute to the converter protection scheme design in Section IV. All three-phase rotor currents are shown in Fig. 3. The same simulation system will also be used for the protection scheme verification that follows. 


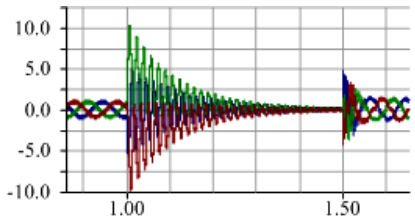

(a)

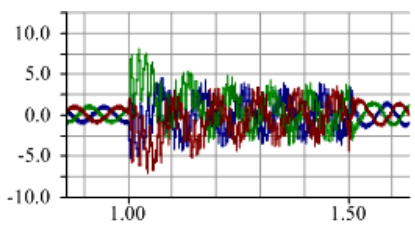

(c)

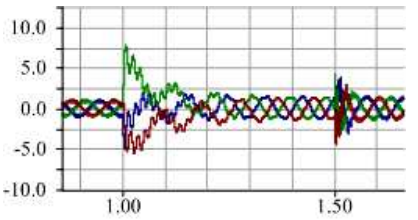

(b)

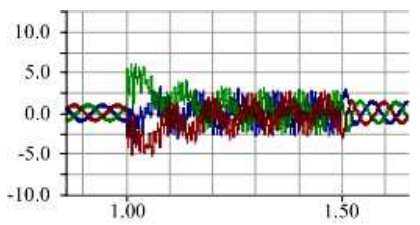

(d)
Fig. 3. Three-phase rotor currents during different fault conditions (for $0.5 \mathrm{~s}$ ): (a) three-phase 1.0p.u. voltage dip; (b) three-phase 0.6p.u. voltage dip; (c) single-phase (phase $a$ ) 1.0p.u. voltage dip; (d) phase-to-phase (phase $b$ to $c$ ) short circuit.

\section{PROTECTION SCHEME BASED ON SERIES DYNAMIC RESISTOR}

The above rotor fault current analysis and simulation highlights a major difference between symmetrical and asymmetrical fault currents. For symmetrical faults, the rotor currents increase abruptly both at the beginning and the end of the fault. The crowbar need only switch on for a short time. For asymmetrical dips, the crowbar does not solve the problem because it needs to be active throughout the duration of the dip, requiring the generator to be disconnected from the grid. This can be explained by the difference in flux components for different faults [16].

In this section, a new protection scheme based on a series dynamic resistor is proposed which also combines and coordinates the existing crowbar and DC-chopper protection. A series dynamic resistor is used as the primary protection, with the crowbar circuit used if the series dynamic resistor cannot protect because of a deteriorating situation. The crowbar is engaged only at the beginning or the end of the fault, if required. The DCchopper is used for DC-link overvoltage limitation.

\section{A. Switching Strategy}

It is observed in the above section that asymmetrical faults are more hazardous than symmetrical faults for the DFIG because of the continuous over-current in the rotor. From the above overcurrent analysis a switching strategy is devised to determine when to engage the protection measures using current thresholds.

1) Protection engaged: The voltage change is not as abrupt as the current and can be shared by the series dynamic resistor. For the DC-link voltage, its change can be further reduced by the DCchopper. Therefore, only rotor currents are monitored for series dynamic resistor and crowbar protections.

2) Protection disengaged: The protections themselves can be seen as disturbances. To avoid the protections switching frequently because of the high frequency component of rotor current, the switch off is delayed for a period of the high frequency component, i.e. $t$ delay $=2 \pi(1-s) \omega_{s}$ after all the threephase currents decrease below the threshold value.

The final switching strategy is shown in Fig. 4.

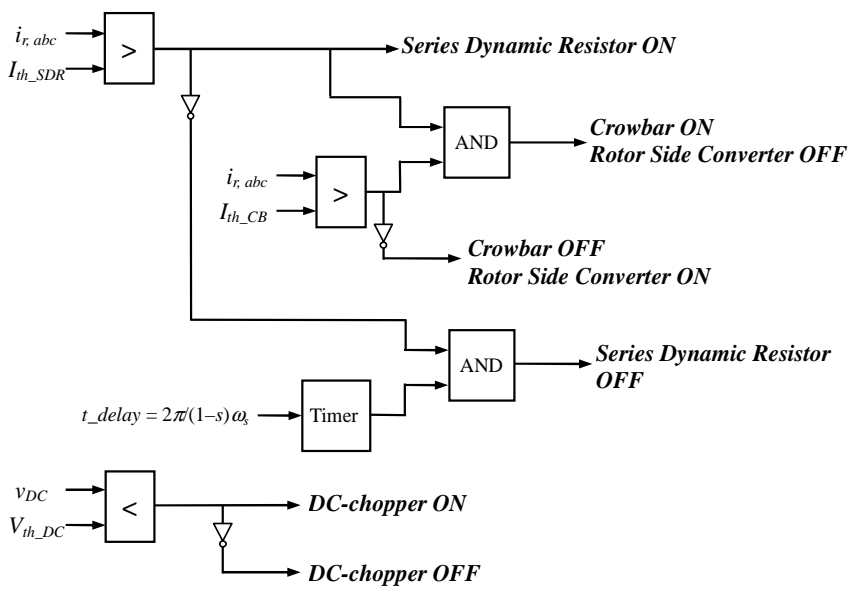

Fig. 4. The combined converter protection switching strategy.

\section{B. Series Dynamic Resistance Calculations}

Resistance values are calculated for the most serious condition (with the highest peak current value): symmetrical voltage dip up to 1.0p.u.. The rotor current expressions are (15) to (19). Due to the small stator resistance, the following approximations are made: $e^{-t / \tau_{s}} \approx 1 ; \tau \approx \tau_{r}$.

Then the current components are expressed as a single trigonometric function as:

$$
\begin{gathered}
i_{D C}=\left\{i_{r a}\left(t_{0}^{-}\right)-\frac{1}{\sigma L_{r}} \frac{\tau_{r}}{1+\tau_{r}^{2}\left(s \omega_{s}\right)^{2}} V_{r} \cos \beta\right. \\
\left.-\frac{1}{\sigma L_{r}} V_{s} \frac{L_{m}}{L_{s}}(1-s) \frac{\tau}{1+\tau^{2} \omega_{r}^{2}}\right\} e^{-\frac{t}{\tau_{r}}} \\
i_{v r}=\frac{V_{r}}{\sigma L_{r}} \frac{\tau_{r}}{\sqrt{1+\tau_{r}^{2} \omega_{r}^{2}}} \sin \left(s \omega_{s} t+\beta+\varphi\right) \\
i_{v r n}=\frac{1}{\sigma L_{r}} V_{s} \frac{L_{m}}{L_{s}}(1-s) \frac{\tau_{r}}{\sqrt{1+\tau_{r}^{2} \omega_{r}^{2}}} \sin \left(\omega_{r} t+\varphi\right)
\end{gathered}
$$

where $\varphi=\tan ^{-1}\left(\frac{1}{\tau_{r} \omega_{r}}\right)$

Considering the amplitude of each component at the maximum current value:

$$
\begin{aligned}
i_{r a, \max } & =i_{r a}\left(t_{0}^{-}\right)-\frac{1}{\sigma L_{r}} V_{s} \frac{L_{m}}{L_{s}}(1-s) \frac{\tau_{r}}{1+\tau_{r}^{2} \omega_{r}^{2}} \\
& +\frac{V_{r}}{\sigma L_{r}} \frac{\tau_{r}}{\sqrt{1+\tau_{r}^{2} \omega_{r}^{2}}}+\frac{1}{\sigma L_{r}} V_{s} \frac{L_{m}}{L_{s}}(1-s) \frac{\tau_{r}}{\sqrt{1+\tau_{r}^{2} \omega_{r}^{2}}}
\end{aligned}
$$

Also, the boundary conditions are

$$
i_{r a, \max } \leq I_{t h \_S D R} ; V_{r} \leq V_{t h \_R S C} \text {. }
$$

Therefore, (48), (49) is an equation where $\tau_{r}$ can be solved. With the protection schemes $\tau_{r}=\frac{\sigma L_{r}}{R_{r}+R_{\text {protection }}}$

Then the critical resistance value $R_{\text {protection }}$ can be calculated. If the rotor fault currents still cannot be limited effectively, the crowbar can be used as further protection. The total resistance is $R_{\text {protection }}$, includes $R_{S D R}$ and $R_{C B}$. The current-limiting function is provided by the series dynamic resistor, hence the critical criteria of crowbar resistance is the voltage across it must be within the rotor voltage limit, for its shunt connection: $R_{C B} \times i_{r \text { max }} \leq V_{r \text { max }}$. So the crowbar resistance is a small contribution to the total $R_{\text {protection }}$. 
This is simpler than using crowbar protection alone, where the resistance has a lower and upper limit. The minimum value is restricted by the rotor winding current limit, while the maximum is set by the voltage limit at the converter terminals [8].

\section{SimULATION RESULTS}

The proposed converter protection method is verified by PSCAD/EMTDC simulations. The generator parameters are listed in the Appendix. The faults simulated are:

1) a three-phase voltage dip of 0.95 p.u. for $0.2 \mathrm{~s}$;

2) a single phase (phase $a$ ) grounding for $0.2 \mathrm{~s}$;

3 ) a two-phase short-circuit (phase $b$ to $c$ ) for $0.2 \mathrm{~s}$; and

4) a three-phase voltage dip of 0.6p.u. for 1.0s.

The threshold values for calculating $R_{S D R}$ and $R_{C B}$ are set as $I_{\text {th_SDR }}=1.5$ p.u., $I_{t h \_C B}=1.8$ p.u.. Rotor slip is $s=-0.2$ p.u. preceding the faults.

(a)

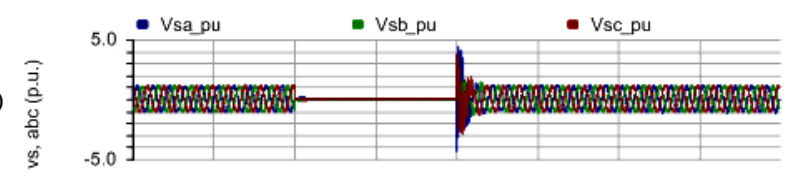

(b)

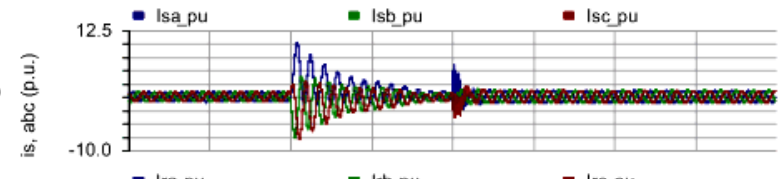

(c)

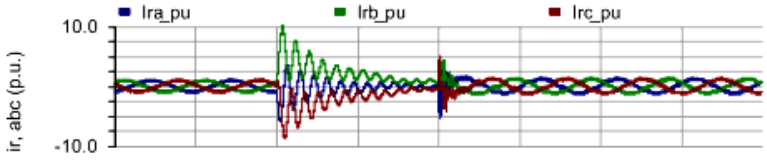

(d)

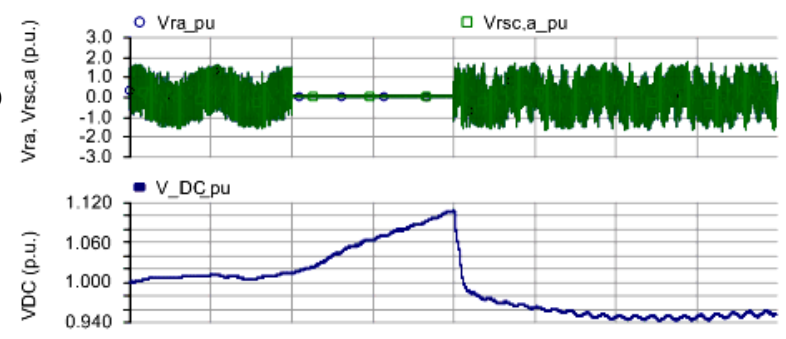

(f)

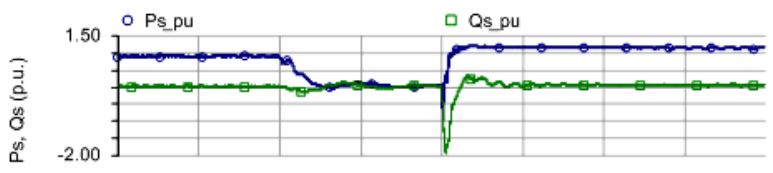

(g)

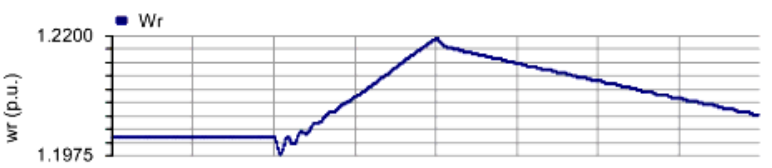

(h)

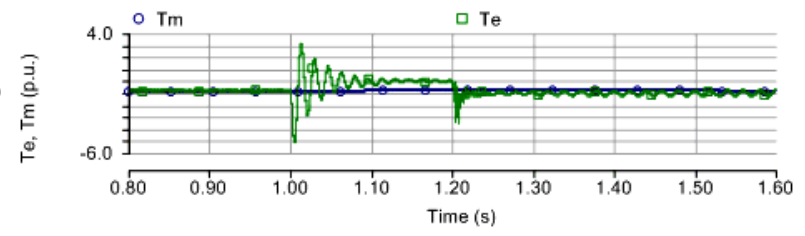

Fig. 5. Three-phase 0.95p.u. voltage dip for $0.2 \mathrm{~s}$ without protection: (a) threephase stator voltages $v_{s a, b, c}$ (p.u.); (b) three-phase stator currents $i_{s a, b, c}$ (p.u.); (c) three-phase rotor currents $i_{r a, b, c}$ (p.u.); (d) phase- $a$ rotor voltage $v_{r a}$ (p.u.) and phase- $a$ RSC voltage $v_{r s c, a}$ (p.u.); (e) DC-link voltage $v_{D C}$ (p.u.); (f) stator side active power $P_{s}$ (p.u.) and reactive power $Q_{s}$ (p.u.); (g) rotor speed $\omega_{r}$ (p.u.); (h) electrical torque $T_{e}$ (p.u.) and mechanical torque $T_{m}$ (p.u.).
From (48), (49), $\tau_{r}=0.2041$ p.u.; $R_{\text {protection }}=0.987$ p.u. $=0.59 \Omega$. Then the selected resistance values are $R_{S D R}=0.5 \Omega, R_{C B}=0.09 \Omega$. The value of DC-chopper resistance is not so critical as it is only related to the DC-link voltage, so here choose $R_{D C C}=0.5 \Omega$.

(a)

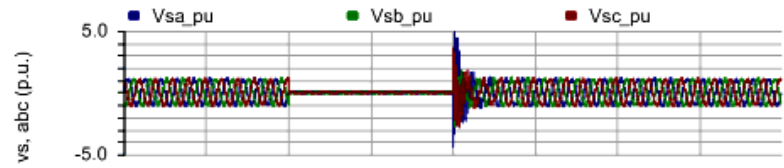

(b)

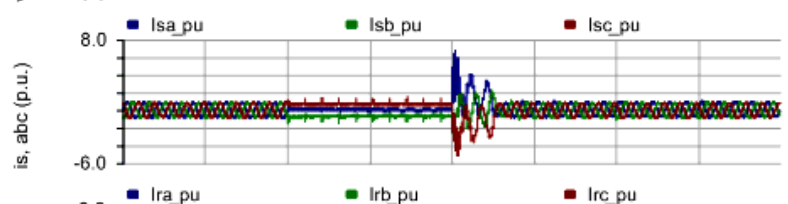

(c)

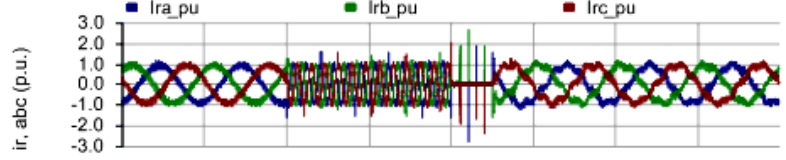

(d)

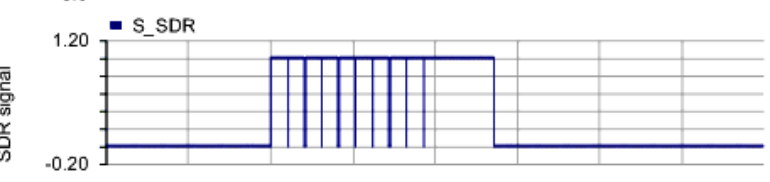

(e)

1.20 - S_CB

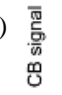

0.20

(f)

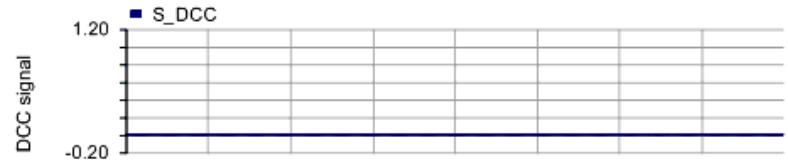

(g)

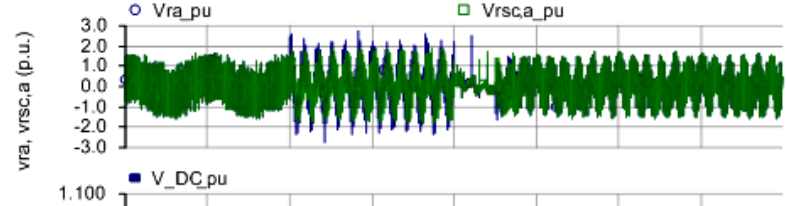

(h)

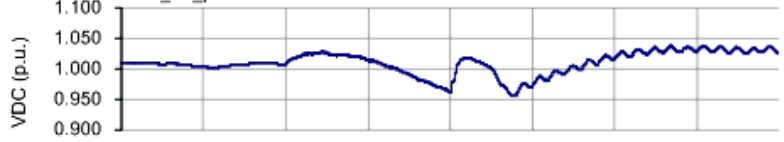

(i)

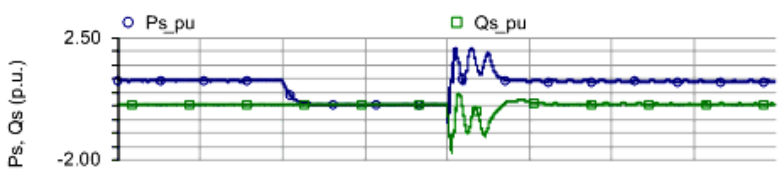

(j)

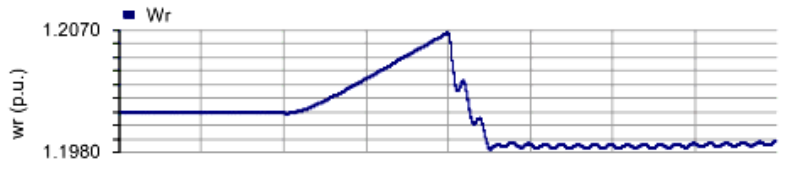

(k)

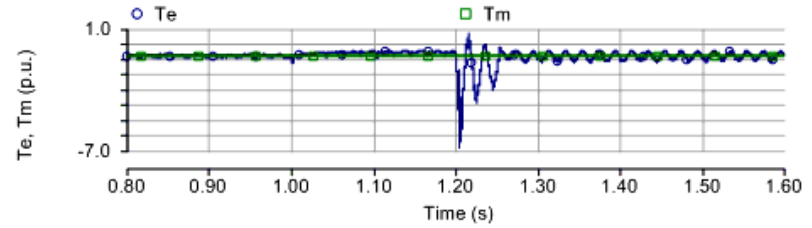

Fig. 6. Three-phase 0.95 p.u. voltage dip for $0.2 \mathrm{~s}$ with converter protection: (a) three-phase stator voltages $v_{s a, b, c}$ (p.u.); (b) three-phase stator currents $i_{s a, b, c}$ (p.u.); (c) three-phase rotor currents $i_{r a, b, c}$ (p.u.); (d) SDR switching signal $S_{S D R}$; (e) crowbar switching signal $S_{C B}$; (f) DC-chopper switching signal $S_{D C C}$; (g) phase- $a$ rotor voltage $v_{r a}$ (p.u.) and phase- $a$ RSC voltage $v_{r s c, a}$ (p.u.); (h) DC-link voltage $v_{D C}$ (p.u.); (i) stator side active power $P_{s}$ (p.u.) and reactive power $Q_{s}$ (p.u.); (j) rotor speed $\omega_{r}$ (p.u.); (k) electrical torque $T_{e}$ (p.u.) and mechanical torque $T_{m}$ (p.u.). 


\section{A. Symmetrical Fault Condition}

Figs. 5 and 6 show the system response to a 0.95 p.u. voltage dip for $0.2 \mathrm{~s}$ with and without protection respectively. In the simulation without protection, the rotor-side converter is blocked during the fault. The rotor currents reach around 10.0p.u. for the most serious phase. DC-link voltage and rotor speed both increase until the fault is cleared. Large electrical torque fluctuations occur.

In Fig. 6, series dynamic resistor is switched in 10 times in total to limit the rotor current. During the recovery of the fault, crowbar is switched in for 5 times with the series dynamic resistor connected as the rotor current increases beyond the crowbar threshold. The simulation results show that with series dynamic resistor protection, the first torque peak is safely avoided, while crowbar is helpful for protection during fault recovery. The rotor current amplitude is limited within 1.5p.u., as required. This also restricts the DC-link voltage increase (less than 0.05p.u. in Fig. 6). The DC-chopper function is not required. The rotor speed increase is effectively restrained, from 1.2p.u. to 1.207 p.u. (1.22p.u. for without protection case).

The large 5.0p.u. torque fluctuation at the start of the fault is avoided; compare Fig. 5 to Fig. 6 with the series dynamic resistor. However, a 7.0p.u. torque fluctuation occurs during the fault recovery phase in Fig. 6 . This is due to the crowbar protection switching in as a further protection measure. The individual crowbar and SDR torque performances will be compared in Part $C$ which shows that all of the 7.0p.u. torque pulsation that occurs at fault recovery is due to the crowbar circuit, Fig. 10 (d) and (e).

Although there is no rotor voltage monitoring in the switching strategy, it is still limited effectively to the value before the fault because of the voltage sharing ability of the series dynamic resistor. The rotor voltages display switching frequency components due to the pulse width modulation (PWM) of the rotor-side converter. The high voltage is shared across the series resistor and the converter which results in a lower converter side voltage ( $v_{r s c, a}$ in Fig. 7).

Large transients happen during the fault clearing mainly due to the impact of crowbar protection switching, but together with series dynamic resistor protection, the disturbances disappear after about $0.05 \mathrm{~s}$. It should be noted that the crowbar is used in this particular case, but is not a necessary requirement under all faults.

\section{B. Asymmetrical Fault Conditions}

Figs. 8 and 9 show the system responses during asymmetrical fault conditions. The rotor currents are also limited within 1.5p.u.. For the phase- $a$ fault in Fig. 8, the series dynamic resistor and crowbar protection switching events are similar to the symmetrical fault conditions. However, there is one period of DC-chopper switching because of the gradual increase of DClink voltage to 1.1p.u.. Instead of increasing, the rotor speed decreases because the DFIG is still under control with active power supplied to the grid. An overspeed condition is avoided as the electrical torque balances the mechanical torque from the wind turbine's blade system.

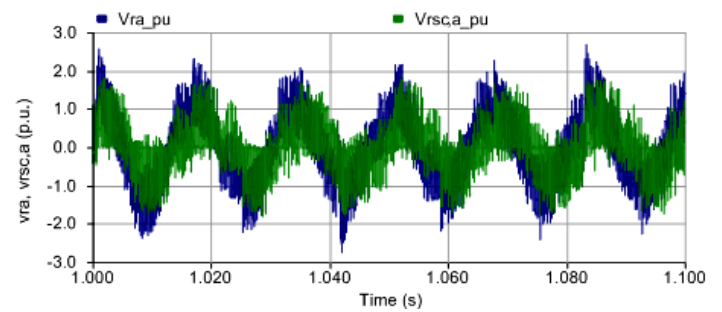

Fig. 7. The rotor voltage $v_{r a}$ (p.u.) and rotor-side converter voltage $v_{r s c, a}$ (p.u.) comparison (zoomed from $1 \mathrm{~s}$ to $1.1 \mathrm{~s}$ ).

(a)

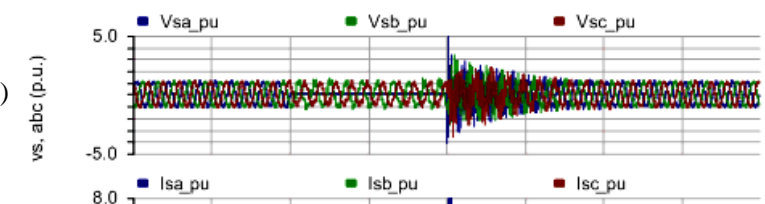

(b)

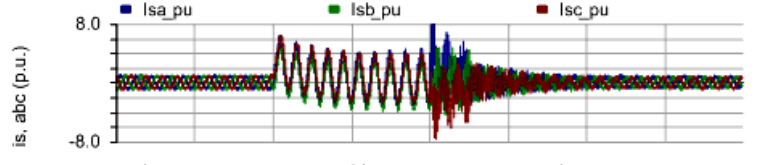

(c)

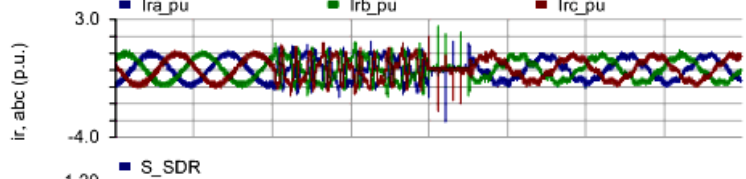

(d)

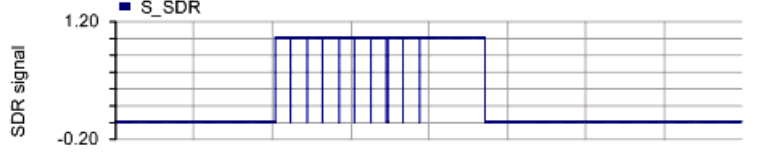

(e)
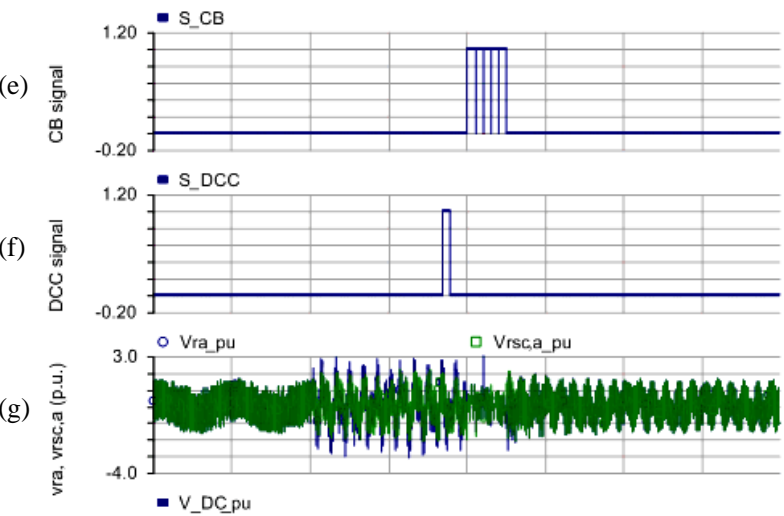

(h)
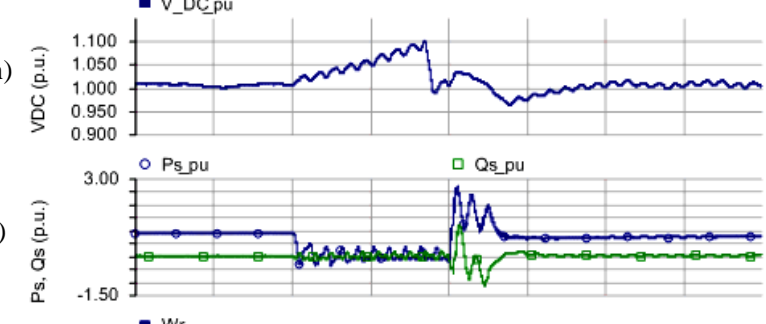

(j)
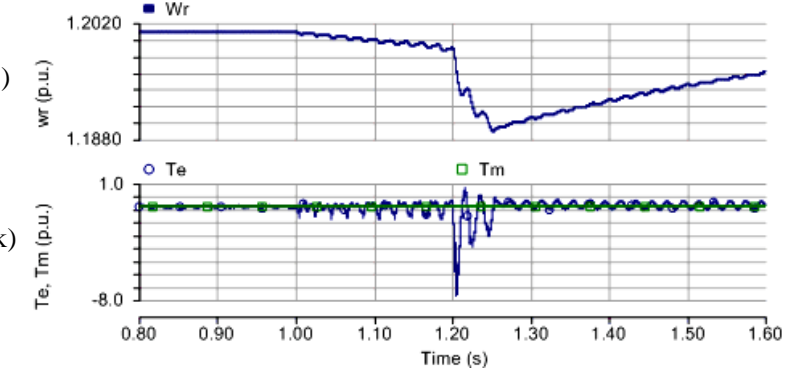

Fig. 8. Phase $a 1.0$ p.u. voltage dip for $0.2 \mathrm{~s}$ with converter protection: (a) threephase stator voltages $v_{s a, b, c}$ (p.u.); (b) three-phase stator currents $i_{s a, b, c}$ (p.u.); (c) three-phase rotor currents $i_{r a, b, c}$ (p.u.); (d) SDR switching signal $S_{S D R}$; (e) crowbar switching signal $S_{C B}$; (f) DC-chopper switching signal $S_{D C C}$; (g) phase- $a$ rotor voltage $v_{r a}$ (p.u.) and phase- $a$ RSC voltage $v_{r s c, a}$ (p.u.); (h) DC-link voltage $v_{D C}$ (p.u.); (i) stator side active power $P_{s}$ (p.u.) and reactive power $Q_{s}$ (p.u.); (j) rotor speed $\omega_{r}$ (p.u.); (k) electrical torque $T_{e}$ (p.u.) and mechanical torque $T_{m}$ (p.u.). 
(a)
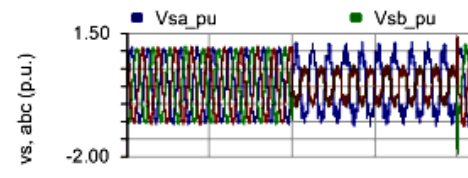

2.00 Isa pu

- Isb_pu

(b)

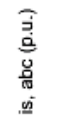

(c)

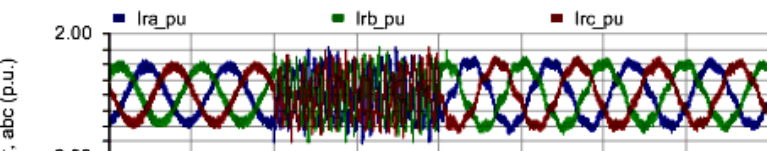

(d)

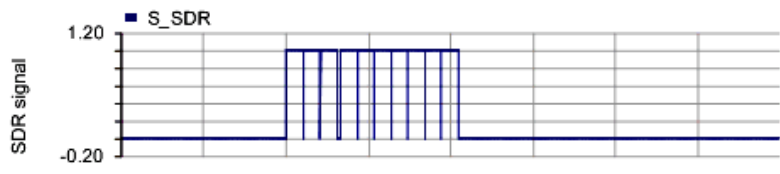

(e)

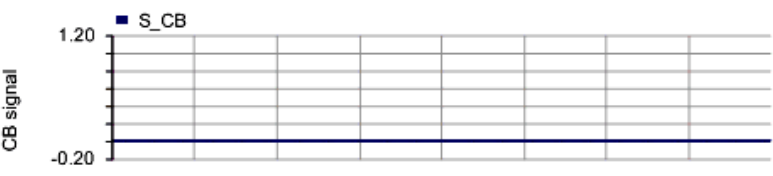

(f)

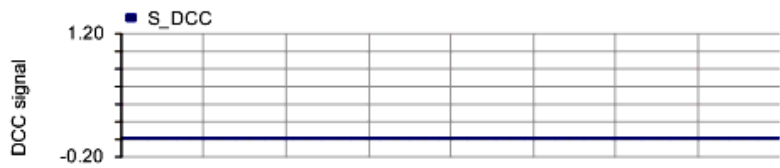

(g)

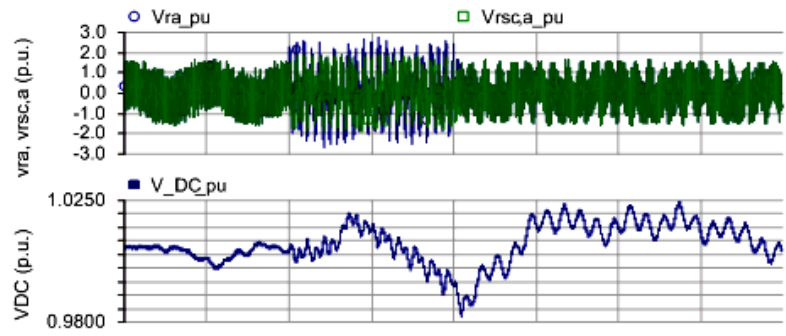

(i)

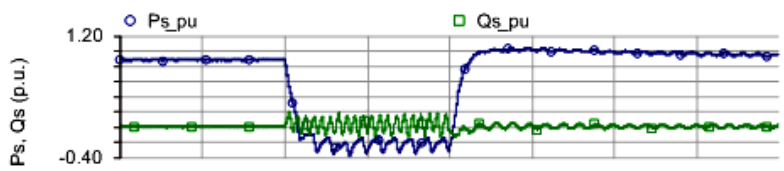

- $-\mathrm{Wr}_{\mathrm{r}}$

(j)

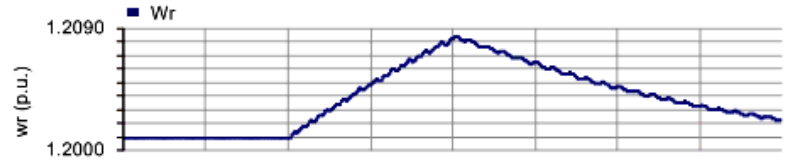

(k) $\stackrel{\Xi}{\llcorner}$

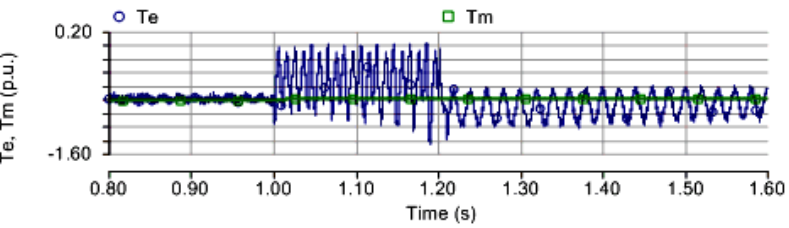

Fig. 9. Phase $b$ to $c$ short circuit for $0.2 \mathrm{~s}$ with converter protection: (a) threephase stator voltages $v_{s a, b, c}$ (p.u.); (b) three-phase stator currents $i_{s a, b, c}$ (p.u.); (c) three-phase rotor currents $i_{r a, b, c}$ (p.u.); (d) SDR switching signal $S_{S D R}$; (e) crowbar switching signal $S_{C B}$; (f) DC-chopper switching signal $S_{D C C}$; (g) phase- $a$ rotor voltage $v_{r a}$ (p.u.) and phase- $a$ RSC voltage $v_{r s c, a}$ (p.u.); (h) DC-link voltage $v_{D C}$ (p.u.); (i) stator side active power $P_{s}$ (p.u.) and reactive power $Q_{s}$ (p.u.); (j) rotor speed $\omega_{r}$ (p.u.); (k) electrical torque $T_{e}$ (p.u.) and mechanical torque $T_{m}$ (p.u.).

The phase $b$ to $c$ short-circuit in Fig. 9, in terms of fault current, is less serious than in the single-phase case. There is no need for both crowbar and DC-chopper operation. The series dynamic resistor is effective in this condition. But in terms of stator voltage, this is more serious than for a single-phase fault. (a)

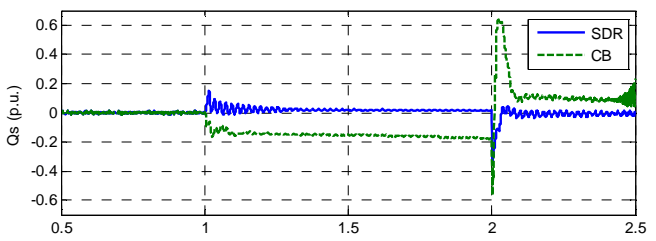

(b)

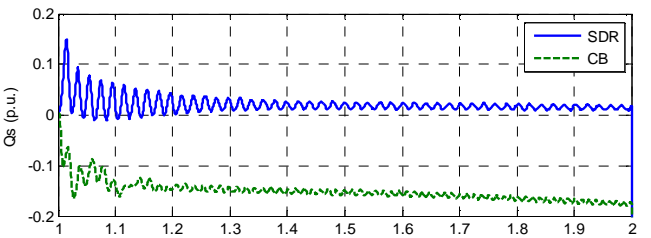

(c)

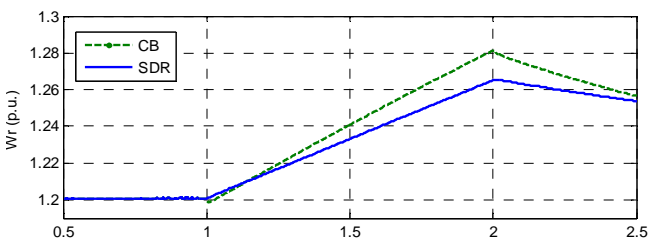

(d)

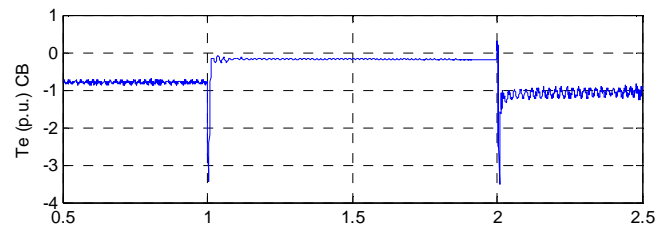

(e)

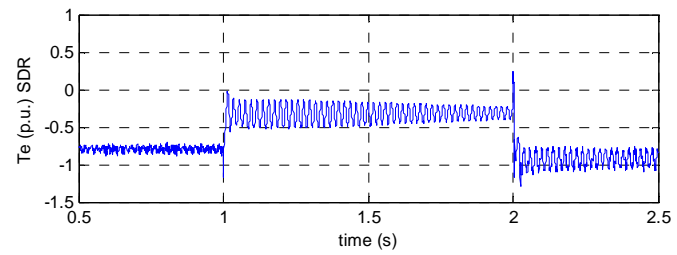

Fig. 10. System response comparison between crowbar and series dynamic resistor protections, voltage dip of $0.6 \mathrm{p} . \mathrm{u}$. for $2 \mathrm{~s}$ : (a) stator-side reactive power $Q_{s}$ (p.u.); (b) zoomed reactive power $Q_{s}$ (p.u.); (c) rotor speed $\omega_{r}$ (p.u.); (d) electrical torque $T_{e}$ (p.u.) with $\mathrm{CB}$ protection; (e) electrical torque $T_{e}$ (p.u.) with SDR protection.

There are much larger power and electrical torque fluctuations during the fault. This results in gradual increase of rotor speed, from 1.20p.u. to 1.21 p.u. but this is not serious.

The two asymmetrical conditions result in fluctuations after stator voltage recovery. Although most of the variables are under control, these fluctuations should be studied in more detail.

\section{Performance Comparison between Crowbar and SDR}

The performance of the crowbar and the series dynamic resistor protection schemes are compared. The reactive power, electrical torque and rotor speed of the DFIG system are simulated and compared in Fig. 10.

Both of the two strategies experience reactive power and electrical torque fluctuations during the fault. However, for crowbar protection, they are much larger. Fig. 10(b) is expanded to show the reactive power supply. It can be seen that with the rotor-side converter connected with the series dynamic resistor protection scheme, no reactive power is absorbed. However, for crowbar protection, the asynchronous machine absorbs reactive power, up to 0.2 p.u.. So in terms of grid voltage recovery, the series dynamic resistor protection has a significant advantage. 
The reactive power and electrical torque ripple are larger with series dynamic resistor protection compared to crowbar protection. This is due to the higher resistance in the rotor winding and DFIG control system performance during faults, which needs further exploration. However, it is clear that the peak torque that occurs at crowbar turn-on and turn-off is significantly higher than that for the series dynamic resistor. This leads to the large torque fluctuation seen in Fig. 6 when the crowbar is engaged. For rotor speed changes they are about 0.02p.u. different at the peak prior to recovery. The series dynamic resistor reduces the rotor over-speed more effectively than the crowbar circuit.

More importantly, the series dynamic resistor has a much smaller impact than the crowbar, especially during switching-off. Improper crowbar switch-off strategy (without the coordination of controller reference setting [4]) can cause frequent switching which affects fault recovery. This can also be seen from the comparison of voltage recovery in Figs. 8 and 9. Without crowbar switching, the voltage recovery for the two-phase shortcircuit shows minimal fluctuation.

\section{APPLICATION DISCUSSIONS}

\section{A. The Switch Time of the Bypass-Switch}

In practical applications, the switch time may be an issue, especially for serious fault protection and recovery when fast switching response is required e.g., some crowbar thyristor switches cannot interrupt the current before zero-crossing [8]. This will influence the protection performance. In the above simulations, switching times of the crowbar and series dynamic resistor power-electronic switches are considered by disabling the interpolation in PSCAD/EMTDC. This solves the conflict between immediate switching-operation with simulation time step The simulation time step is set as $20 \mu$ s, so the actual switch time for IGBT is $20 \mu \mathrm{s}$, which is enough for the IGBTs in applications (commonly several $\mu$ s [17]).

\section{B. Switch Normal Operation Losses}

The series dynamic resistor is here realized by a powerelectronic switch. However, the bypass switch that is closed during normal operation will produce additional losses, specifically device on-state losses. But compared to the stator side braking resistor bypass-switches [13], this is far lower due to the lower power rating on the rotor side.

\section{CONCLUSION}

Converter protection is necessary for DFIG wind power generation systems during fault conditions. In this paper, various resistor protection schemes are reviewed. The purpose of a series dynamic resistor is to avoid the frequent use of crowbar shortcircuit, to maximize the operation time of the rotor-side converter, and to reduce torque fluctuations during protection operation. The rotor currents during various fault conditions are discussed and current expressions are given to instruct the design of the protection scheme. Resistance calculations for the series dynamic resistor and crowbar using the expression of maximum rotor current are described.
The series dynamic resistor can operate with the rotor-side converter control functioning. For the control of the grid-side converter to DC-link bus voltage, the resumption time can be shorter than for a system with normal active crowbar protection. This is helpful for resuming normal control and provides reactive power for grid voltage support. During this process, inspection of the reactive power, electrical torque, and rotor speed fluctuations show that the proposed method enhances DFIG fault ride-through capability.

\section{APPENDIX}

TABLE III GENERATOR PARAMETERS

\begin{tabular}{l|l||l|l}
\hline Parameter & Value & Parameter & Value \\
\hline Rated power $P_{n}$ & $2 \mathrm{MW}$ & Ratio $N_{s} / N_{r}$ & 0.63 \\
\hline Rated stator voltage $V_{s n}$ & $690 \mathrm{~V}$ & Inertia constant $H$ & $3.5 \mathrm{~s}$ \\
\hline Rated frequency $f_{s}$ & $50 \mathrm{~Hz}$ & Pole pair no. $P_{p}$ & 2 \\
\hline Stator leakage inductance $L_{l s}$ & 0.105 p.u. & Stator resistance $R_{s}$ & 0.0050 p.u. \\
\hline Rotor leakage inductance $L_{l r}$ & 0.100 p.u. & Rotor resistance $R_{r}$ & 0.0055 p.u. \\
\hline Magnetizing inductance $L_{m}$ & 3.953 p.u. & & \\
\hline
\end{tabular}

\section{REFERENCES}

[1] British Wind Energy Association. Offshore wind. Available: http://www.bwea.org/offshore/ info.html

[2] The European Wind Energy Association. European Statistics. Available: http://www.ewea.org/index.php?id=1486

[3] P. J. Tavner, J. Xiang, and F. Spinato, "Reliability analysis for wind turbines," Wind Energy, 2007, vol. 10, pp. 1-18, [Online]. Available: http://www3.interscience.wiley.com/cgibin/fulltext/112701014/PDFSTART

[4] J. Morren, and S.W.H. de Haan, "Ridethrough of wind turbines with doubly-fed induction generator during a voltage dip," IEEE Trans. Energy Convers., vol. 20, no. 2, pp. 435-441, Jun. 2005.

[5] I. Erlich, J. Kretschmann, J. Fortmann, S. Mueller-Engelhardt, and H. Wrede, "Modeling of wind turbines based on doubly-fed induction generators for power system stability studies," IEEE Trans. Power Syst., vol. 22, no. 3, pp. 909-919, Aug. 2007.

[6] D. Xiang, R. Li, P. J. Tavner, and S. Yang, "Control of a doubly fed induction generator in a wind turbine during grid fault ride-through," IEEE Trans. Energy Convers., vol. 21, no. 3, pp. 652-662, Sep. 2006.

[7] P. S. Flannery and G. Venkataramanan, "A fault tolerant doubly fed induction generator wind turbine using a parallel grid side rectifier and series grid side converter," IEEE Trans. Power Electron., vol. 23, no. 3, pp. 1126-1135, May 2008.

[8] J. Morren and S. W. H. de Haan, "Short-circuit current of wind turbines with doubly fed induction generator," IEEE Trans. Energy Convers., vol. 22, no. 1, pp. 174-180, Mar. 2007.

[9] P. Zhou and Y. He, "Control strategy of an active crowbar for DFIG based wind turbine under grid voltage dips," in Proc. Int. Conf. Electrical Machines and System. 2007, Seoul, Korea, Oct. 8-11, 2007.

[10] M. Rodríguez, G. Abad, I. Sarasola, and A. Gilabert, "Crowbar control algorithms for doubly fed induction generator during voltage dips," in Proc. 11th Eur. Conf. Power Electron. Appl., Dresden, Germany, Sep. 11-14, 2005.

[11] I. Erlich, H. Wrede, and C. Feltes, "Dynamic behavior of DFIG-based wind turbines during grid faults," in Proc. Power Convers. Conf., Nagoya, Japan, Apr. 2-5, 2007.

[12] J. F. Conroy and R. Watson, "Low-voltage ride-through of a full converter wind turbine with permanent magnet generator," IET Renew. Power Gener., vol. 1, no. 3, pp. 182-189, 2007.

[13] A. Causebrook, D. J. Atkinson, and A. G. Jack, "Fault ride-through of large wind farms using series dynamic braking resistors (March 2007)," IEEE Trans. Power Syst., vol. 22, no. 3, pp. 966-975, Aug. 2007.

[14] J. López, P. Sanchis, X. Roboam, and L. Marroyo, "Dyanmic behavior of the doubly fed induction generator during three-phase voltage dips," IEEE Trans. Energy Convers., vol. 22, no. 3, pp. 709-717, Sep. 2007. 
[15] M. S. Vicatos and J. A. Tegopoulos, "Transient state analysis of a doubly-fed induction generator under three phase short circuit," IEEE Trans. Energy Convers., vol. 6, no. 1, pp. 62-68, Mar. 1991.

[16] J. López, E. Gubía, P. Sanchis, X. Roboam, and L. Marroyo, "Wind turbines based on doubly fed induction generator under asymmetrical voltage dips," IEEE Trans. Energy Convers., vol. 23, no. 1, pp. 321-330, Mar. 2008.

[17] S. Castagno, R. D. Curry, and E. Loree, "Analysis and comparison of a fast turn-on series IGBT stack and high-voltage-rated commercial IGBTs," IEEE Trans. Plasma Science, vol. 34, no. 5, pp 1692-1696, Oct. 2006.

\section{BIOGRAPHIES}

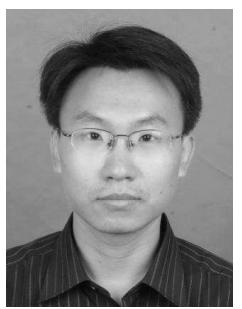

Jin Yang (S'08) was born in Liaoning, China in 1980. $\mathrm{He}$ received his B.Eng. and M.Sc. degrees from North China Electric Power University, Hebei, China, in 2003 and 2006, respectively.

$\mathrm{He}$ is now pursuing his Ph.D. degree in the Department of Electronics and Electrical Engineering, University of Glasgow, Glasgow, U.K. His research interests include wind power generation system protection and wind power economics.

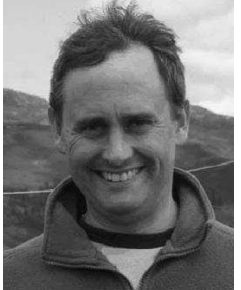

John E. Fletcher received the B.Eng. (first class honours) degree from Heriot-Watt University, Edinburgh, U.K. in 1991, and the Ph.D. degree from Heriot-Watt University, Edinburgh, U.K. in 1995, both in Electrical and Electronic Engineering.

He was with Heriot-Watt University until 2007 and is currently Senior Lecturer at the University of Strathclyde, Glasgow, UK. His research interests include power electronics, drives and energy conversion, and manages research projects including distributed and renewable integration, silicon-carbide electronics, pulsedpower applications of power electronics and the design and control of electrical machines. Dr. Fletcher is a chartered Engineer in the U.K. and a Fellow of the Institution of Engineering and Technology.

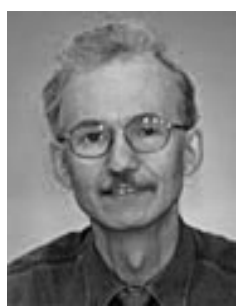

John O'Reilly (M'81-SM'00) received the B.Sc., $\mathrm{Ph} . \mathrm{D}$., and D.Sc. degrees in engineering from Queens University, Belfast, U.K., in 1972, 1976, and 1985, respectively.

Currently, he is a Professor of control engineering in the Department of Electronics and Electrical Engineering, University of Glasgow, Glasgow, U.K. His interests include power system dynamics and control with renewable energy. 